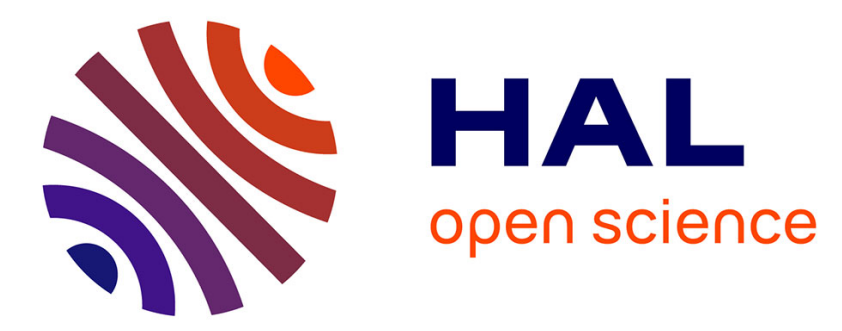

\title{
Interest of multi-modal imaging in bilateral lesions of basal ganglia: A case report of a post-anoxic dystonia
}

Pierre-Maxime David, Nicolas Icard, Jean-Yves Gauvrit, Marc Vérin, Florence Le Jeune

\section{- To cite this version:}

Pierre-Maxime David, Nicolas Icard, Jean-Yves Gauvrit, Marc Vérin, Florence Le Jeune. Interest of multi-modal imaging in bilateral lesions of basal ganglia: A case report of a post-anoxic dystonia. European Journal of Nuclear Medicine and Molecular Imaging, 2016, 43 (11), pp.2098-2099. 10.1007/s00259-016-3413-6 . hal-01371659

HAL Id: hal-01371659

https://hal-univ-rennes1.archives-ouvertes.fr/hal-01371659

Submitted on 18 Oct 2016

HAL is a multi-disciplinary open access archive for the deposit and dissemination of scientific research documents, whether they are published or not. The documents may come from teaching and research institutions in France or abroad, or from public or private research centers.
L'archive ouverte pluridisciplinaire $\mathbf{H A L}$, est destinée au dépôt et à la diffusion de documents scientifiques de niveau recherche, publiés ou non, émanant des établissements d'enseignement et de recherche français ou étrangers, des laboratoires publics ou privés. 


\title{
Interest of multi-modal imaging in bilateral lesions of basal ganglia: A case report of a post-anoxic
} dystonia.

\section{Name of authors:}

Pierre-Maxime David ${ }^{1}$ MR, Nicolas Icard ${ }^{1} \mathrm{MD}$, Jean-Yves Gauvrit ${ }^{2} \mathrm{MD}$, PhD Marc Vérin ${ }^{3} \mathrm{MD}$, PhD, Florence Le Jeune ${ }^{1} \mathrm{MD}, \mathrm{PhD}$

${ }^{1}$ Department of Nuclear Medicine, Eugene Marquis Center, Rennes, France

${ }^{2}$ Department of Neuroradiology, Rennes University Hospital, Rennes, France

${ }^{3}$ Department of Neurology, Rennes University Hospital, Rennes, France

\section{Adress of corresponding author:}

Adress : Pierre-Maxime David, Service de Médecine Nucléaire, Centre Eugene Marquis, Rue de la Bataille Flandres Dunkerque 35042 Rennes Cedex, France

E-mail adress: pierremaxime.david@ hotmail.com

Tel.: +33299253014

Fax: +33299253240

\begin{abstract}
:
Objectives: We report the case of a 16-year-old patient with progressive generalized choreo-dystonia that appeared two months after a suicide attempt by hanging associated with a cardiorespiratory arrest. An initial magnetic resonance imaging (MRI) brain scan was judged normal by radiologists. Discordance between clinical presentation and morphological imaging led to the hypothesis of a psychogenic dystonia but striatal lesions were suspected by neurologists.

Methods: A second MRI high field was performed and the patient also underwent ${ }^{123}$ I-fluopane single photon emission computed tomography (SPECT). MRI and SPECT fusion images were analysed.

Results: The second MRI failed to reveal any lesions involving the basal ganglia. ${ }^{123}$ I-fluopane-SPECT, however, highlighted bilateral posterior putaminal presynaptic dopaminergic denervation. Post hoc analysis of MRI and SPECT fusion images confirmed bilateral posterior putamen lesions, with low signal intensity on DWI, confirming the diagnosis of postanoxic generalized dystonia.

Conclusions: We report this case to highlight the utility of multimodal imaging in diagnosis of bilateral lesions in difficult neurologic disorders where there is discordance between the clinical presentation and morphological brain imaging.
\end{abstract}

Keywords: 123I-FP-CIT-SPECT; MRI; Multi-modal Imaging; Dystonia; Cerebral Anoxia

Acknowledgments We would like to thank Odile Audrain for her help 


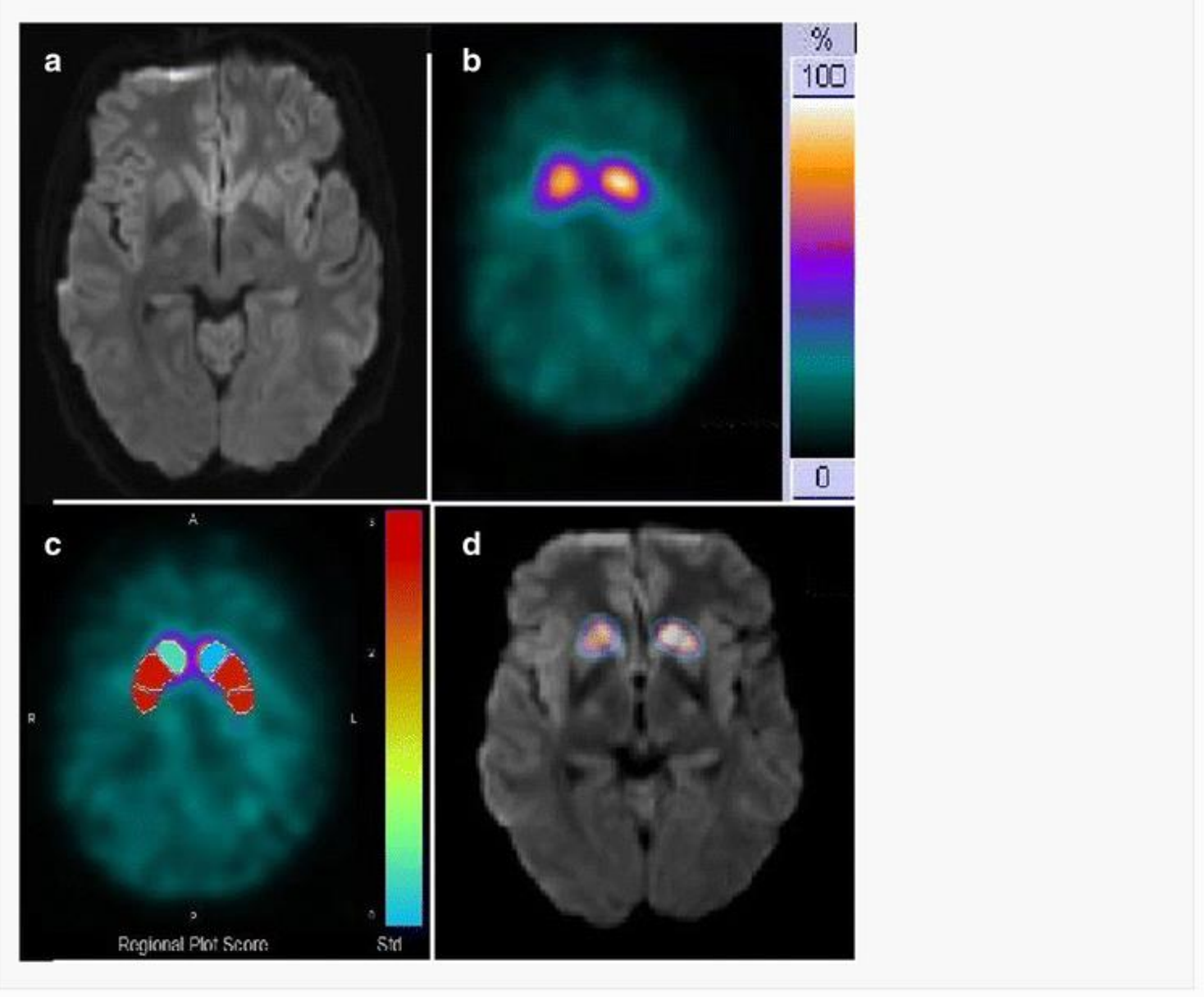

\section{Image of the month}

A 16-year-old patient had been resuscitated from a cardiorespiratory arrest of fifteen minutes following an attempted suicide by hanging. An emergency brain computed tomography (CT) was normal. Electroencephalography showed no abnormalities. The parents reported mood disorders with consumption of cannabis during the period preceding the suicide attempt. He had a neurologically favourable outlook but two months after, the patient had increasing difficulty walking with generalized dystonia associated to sad mood with dark thoughts. First magnetic resonance imaging (MRI) at this time was judged to be normal (a).

The discordance between clinical presentation and normal morphological imaging, with two symptom-free months, led to the hypothesis of psychogenic dystonia but clinicians suspected nigrostriatal lesions. A ${ }^{123}$ Ifluopane single-photon emission computed tomography (SPECT) was performed to highlight a dopaminergic deficit (1),and showed a decrease of radiotracer uptake in the bilateral posterior putamen, with normal uptake in the caudate (b), confirmed by comparison with a database of healthy, age-matched individuals (GEMS, DaTQUANT®)(c). A second MRI 3T was performed but first reading failed to highlight any lesion in the basal ganglia. MRI and SPECT fusion images revealed a decrease of tracer uptake with low signal intensity on DWI in in the bilateral posterior putamen, confirming anoxic striatal bilateral lesions (d). Cases of delayed-onset generalized dystonia due to cerebral hypoxic damage have been described (2), with isolated bilateral lesions in the basal ganglia(3) but not always clear in morphological brain imaging. 
To our knowledge, this is the first case of postanoxic dystonia to have been diagnosed by fusion SPECT with MRI, demonstrating the utility of multi-modal imaging for diagnosis of bilateral lesions in difficult neurological disorders.(4)

\section{Compliance with Ethical Standards}

Funding: The authors declare that they received no funding for tihs work of any source.

Conflict of Interest: Pierre-Maxime David, Nicolas Icard, Jean-Yves Gauvrit, Marc Verin, and Florence Le Jeune declare that they have no conflict of interest.

Ethical approval: All procedures performed in studies involving human participants were in accordance with the ethical standards of the institutional and/or national research committee and with the 1964 Helsinki declaration and its later amendments or comparable ethical standards.

Informed consent was obtained from the participant included in the study.

This article does not contain any studies with animals performed by any of the authors.

\section{References}

1. Bajaj N, Hauser RA, Grachev ID. Clinical utility of dopamine transporter single photon emission CT (DaTSPECT) with (123I) ioflupane in diagnosis of parkinsonian syndromes. J Neurol Neurosurg Psychiatry. nov 2013;84(11):1288-95.

2. Kuoppamäki M, Bhatia KP, Quinn N. Progressive delayed-onset dystonia after cerebral anoxic insult in adults. Mov Disord Off J Mov Disord Soc. nov 2002;17(6):1345-9.

3. Burton K, Farrell K, Li D, Calne DB. Lesions of the putamen and dystonia: CT and magnetic resonance imaging. Neurology. juill 1984;34(7):962-5.

4. Calabria F, Ciccariello G, Falcone C, Cascini GL, Schillaci O. A case of Fahr's disease examined by multimodal imaging. Eur J Nucl Med Mol Imaging. déc 2015;42(13):2098-9. 